\title{
1
}

\section{Why Sustainable Business Model Innovation?}

"Just a few years ago, nobody questioned the footprint of our products. The fact that our house insulation products decreased customers' energy consumption was more than good enough. Today, however, we must redesign our business model completely, for instance by no longer using coal as the main energy source in our many factories. We are expected to make our products recyclable and reusable, and we are even faced by a need to make them smarter, by using sensors that connect them to the Internet. Not at least, we need to find new ways of interacting with our customers and other players in collaboration with competitors and different platform-based networks. In order to do that, we need to rethink the whole idea of who we are, what we deliver to whom and how, and how we are going to make a profit."

The CEO of the big, international corporation was excited and uncomfortable at the same time. He had been in the insulation business his whole career. We met him at a roundtable discussion that we facilitated with executives from key companies in the construction industry. During

S. Jørgensen, L. J. T. Pedersen, RESTART Sustainable Business Model Innovation, Palgrave Studies in Sustainable Business In Association with Future Earth, https://doi.org/10.1007/978-3-319-91971-3_1 
the conversation, he told us that his company was searching for innovative and more sustainable solutions along its entire value chain, including designing new products and services, developing new ways of sourcing, manufacturing and prolonging the life of its products and finding new ways of distributing and monitoring them by means of new technology and new alliances.

This is not the only CEO or top-level manager currently experiencing such challenges. During the 15 years we have studied corporate sustainability, we have experienced firsthand that the business landscape has changed tremendously. When we started researching corporate sustainability, the people in charge of corporate social responsibility (CSR) and sustainability issues were typically powerless communication managers with low budgets, who were unwillingly tasked with managing such issues as a small part of their job description. Neither corporate responsibility nor sustainability issues were anchored at the top of the organization. Furthermore, the relatively few stakeholders within the companies who cared about these issues were mostly activists pushing this agenda. Today, however, we get to discuss sustainable business model innovation in boardrooms and executive offices, and sustainability and its implications for business models have become a strategic priority across all industries_-sometimes as a threat, but more and more often as an opportunity.

This does not mean that designing innovative and sustainable business models is a walk in the park. We propose that it is possible, and as we will show you throughout this book, there is a growing body of research within the field of corporate sustainability indicating that companies can be both sustainable and profitable at the same time. There is, however, still a long way to go, and the path toward sustainable business is a rocky and risky one. We argue that sustainable business model innovation requires hard work and even a solid dose of bravery. We also argue that we still lack research-based insights that can guide practitioners who want to embark on the sustainability journey, such as the CEO described above. Our purpose with this book is thus to develop a research-based framework or a map that can empower leaders in their quest for sustainable and profitable business models and that can pave the way for more research on such business model innovation in the near future. 


\subsection{A RESTART of Business Models for a Brighter Future Earth}

We have coined our framework for sustainable business model innovation RESTART. We introduce this framework briefly in the next chapter, and we develop and discuss it in detail in the second part of the book. Before we introduce the framework, we will shortly discuss three interwoven trends that we argue drive the development of new business models and that drive the need for sustainable business model innovations: (1) the sustainability problem, (2) digitalization and the technological opportunity space and (3) changing consumer preferences and lifestyles (Fig. 1.1).

The comprehensive sustainability problem with which we are faced comprises numerous social and environmental challenges that need to be solved. In this age of digitalization, however, companies at the same time find themselves in the midst of an ocean of technological opportunities that allow for new and smarter business models, and societal trends enable companies to deliver their products and services in new ways that are attractive to a new generation of consumers. Taken together, this is fertile ground for business model innovation. Taken together, however, these ongoing trends and drivers also represent many unknown factors that managers need to take into consideration when developing and implementing their strategies.

Managers often ask us how they are supposed to achieve sustainable and profitable business models in practice in this new business landscape. In our talks and strategy seminars, we often use "the dark room" as a
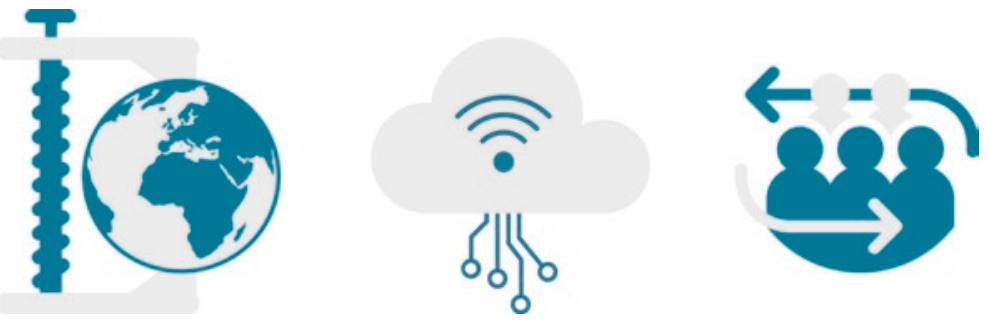

Fig. 1.1 Three trends driving the development of new business models 
metaphorical starting point for sustainable business model innovation. In any innovation process, the light switch is hidden somewhere inside the dark room. Outside of the room-in the light - lies the known territory for the managers and their companies, often illuminated by practices that are woven deep into the culture or the DNA of the company. The sustainability problem, the technological changes we are witnessing and the changes in customers' expectations are all beyond the known part of this territory. It often feels safer for managers and other stakeholders out there in the light, where they can maneuver in safe environments without having to take unnecessary risks. However, as the CEO above describes, contemporary business managers operate in a competitive landscape that requires them to redesign their business models and break loose from business as usual. Often, this involves entering dark rooms in search of the light switch that "turns on" innovative ideas and business models. This also means that they need to start looking at the sustainability problem, the new technologies and the changes in customers' expectations as opportunities, rather than as threats.

In order to find the light switch, the first thing managers need to do is to enter the dark room, which can be challenging in its own right. When entering the dark room, they meet many challenges: the light switch seems to move from time to time and the furniture seems to move around as well. This implies that once they think they have found an innovative solution to a sustainability problem, other factors interfere and complicate the situation - conditions may have changed, competitors may have acted or other players may have entered the industry and changed the rules of the game. True innovators thus need to work together to understand the problem better and to find new solutions that can push them forward toward their goals and objectives — that is, to find the switch that turns on the light.

In the following chapters, we invite you to join us in the hunt for the light switch to sustainable business model innovations. To create a brighter future, everyone needs to contribute to this search-whether you are a researcher, a student, a manager in the middle of an innovation process or a concerned citizen who believes we are in need of a shift toward more sustainable business models. Our experience is that entering such dark rooms may not seem very tempting at first, but it helps to be 
prepared when entering the darkness. This involves conducting the search for new business models based on knowledge and insights that can lead to asking better questions and being more precise in the search for the answers to those questions. The research-based framework RESTART that we develop in this book can support managers in their attempt to rethink, reinvent and reorganize the ways in which they create, deliver and capture value through their business models.

Such innovative efforts are necessary for companies that want to take part in the ongoing movement from a brown to a green economy, from an analog to a digital economy and from an old-fashioned to a modern economy. This book addresses this transition. It discusses why such a transition is needed, how new and smarter business models can be designed and how researchers can study such innovation processes. We argue that there are massive changes going on that require new lenses through which we can understand business. The business landscape has changed comprehensively, and new maps are needed to maneuver in this rapidly changing territory.

The managers of contemporary companies need to identify and step into their dark rooms, and not only that: they also need to inspire their coworkers to join them in the search for the light switch. We propose that many companies have failed to design sustainable business models because they have not yet asked the right questions. This book thus attempts to provide knowledge and insight that can be helpful for asking the questions that can spark the necessary transition toward business models that are fit for the future-whether you are a researcher, a manager, a student, a regulator or a legislator, or just a citizen interested in business, society and the environment.

\subsection{The Methodological Approach of This Book}

This book outlines the RESTART framework, which is a conceptual framework that is intended to capture the characteristics of new business models that can be sustainable and profitable at the same time. We 
moreover consider the framework as a research agenda, as each of the seven components of the framework will require comprehensive research, and toward the end of the book, we point out fruitful avenues for research related to several of these components.

We have developed the framework over a period of many years, through a combination of quantitative, qualitative and action-based research in close collaboration with companies in several sectors. Across several different research projects, we have collected data through structured and unstructured interviews with executives, managers and sustainability officers, which have formed the basis for a deeper understanding of the kinds of changes companies are attempting to make to their business models. We use many of these companies as cases and examples throughout this book, and their business models are used as examples to shed light on various characteristics of more sustainable business models. Among those companies are Norwegian companies, such as Bright Products, Orkla and Norsk Gjenvinning, and international companies, such as The Plastic Bank and Scanship. Structured and unstructured interviews with managers and executives in these companies and others have been central to the empirical inquiry on which the book builds.

In addition, we have conducted surveys and field experiments with companies that also inform our account of the changes taking place and further business model innovations that might become widespread. For instance, our inquiry is informed by our field experiments on sustainability investing in Skandiabanken (Døskeland and Pedersen 2015, 2017), our survey of sustainability practices and performance in Norwegian service firms (Gulbrandsen et al. 2017) and the management control and governance practices in the same firms (Gulbrandsen et al. 2015), as well as our empirical investigations of the relationship between sustainability efforts and consumer trust (Jørgensen et al. 2018).

Finally, we build on secondary data and information from a vast and manifold set of reports, documents and scientific studies that have informed our understanding of the business modeling trends that are ongoing, and that are likely to shape the business models of the future. In 
our research projects in collaboration with the companies outlined above and many others, we have been granted access to numerous documents that have allowed us to dig deeper into how these companies are working in order to adapt their business models to the sustainability problem, technological changes that are underway and changing consumer preferences and lifestyles.

When considering the methodological approach of our book, however, we should also note that we have gradually tested the framework on a variety of managers and executives. We have done so in Executive MBA programs, in company-internal workshops with managers of companies trying to design new and more sustainable business models and in other events with a corporate audience, over a period of several years. This has given us valuable feedback on how concepts are understood and the relative importance of various aspects of the framework and characteristics of business models. We believe that one of the strengths of the framework outlined in this book is that we have continuously tested the ideas upon which the framework rests on both the companies with which we have conducted empirical studies and managers from other companies that are struggling with the same kinds of challenges that this book addresses.

From a scientific point of view, we consider the framework better suited as a point of departure for asking better questions, rather than a framework that gives answers. At the time of writing, we are designing empirical studies-including field experiments, surveys and other research designs - aimed at investigating the seven components of the RESTART framework. This includes studies of sharing-economic business models, alliances for business models at the bottom of the pyramid and circular-economic business models. For this reason, we encourage academic readers of this book to read it as a contribution not just to conceptualizing sustainable business models, but also to the research agenda in which we need plentiful of studies investigating the attempt to align sustainability and profitability when designing and innovating new business models. 


\subsection{Let Us RESTART Sustainable Business Model Innovation}

In 2028, ten years from now, the CEO of the insulation company outlined above will probably have retired, but it will be interesting to see what company he leaves behind. Will he have been successful at innovating its business model to become more sustainable, leveraging new technologies and fit for the future expectations of its customers? In 2028, we will probably look back at 2018 and say, "Why didn't we grab the opportunities then?" We are going to look back and think that at the time it should have been easy to exploit the new technological opportunities to develop new, smarter and more sustainable business models. We will look back at 2018 as the time when one could exploit all the novel technologies comprised in the fourth industrial revolution to make new products and services that have a smaller footprint while delivering high-quality and convenient solutions in line with customer expectations. We argue that achieving this requires a RESTART. In the following chapters, we discuss what such a RESTART might entail, how it can be studied empirically and how managers can utilize such a framework in an attempt to design and implement the business models of the future.

\section{References}

Døskeland, T., \& Pedersen, L. J. T. (2015). Investing with brain or heart? A field experiment on responsible investment. Management Science, 62(6), 1632-1644.

Døskeland, T., \& Pedersen, L. J. T. (2017). Does the wealth of investors matter? Evidence from a field experiment on responsible investment. Working paper, NHH Norwegian School of Economics.

Gulbrandsen, E. A., Jørgensen, S., Kaarbøe, K., \& Pedersen, L. J. T. (2015). Developing management control systems for sustainable business models. Beta: Scandinavian Journal of Business Research, 29(1), 10-25. 
Gulbrandsen, E. A., Jørgensen, S., \& Pedersen, L. J. T. (2017). Sustainability practices and performance in Norwegian knowledge-intensive service companies. Working paper, NHH Norwegian School of Economics.

Jørgensen, S., Pedersen, L. J. T., \& Skard, S. (2018). Does going green build trust? The relationship between sustainability efforts, perceived innovativeness and trust. Working paper, NHH Norwegian School of Economics.

Open Access This chapter is licensed under the terms of the Creative Commons Attribution-NonCommercial-NoDerivatives 4.0 International License (http:// creativecommons.org/licenses/by-nc-nd/4.0/), which permits any noncommercial use, sharing, distribution and reproduction in any medium or format, as long as you give appropriate credit to the original author(s) and the source, provide a link to the Creative Commons license and indicate if you modified the licensed material. You do not have permission under this license to share adapted material derived from this book or parts of it.

The images or other third party material in this chapter are included in the chapter's Creative Commons license, unless indicated otherwise in a credit line to the material. If material is not included in the chapter's Creative Commons license and your intended use is not permitted by statutory regulation or exceeds the permitted use, you will need to obtain permission directly from the copyright holder.

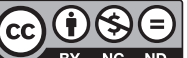

